\title{
Evaluating aggregate stability, surface properties and disintegration behavior of bauxite residue induced by $\mathrm{Ca} / \mathrm{Na}$
}

by Xue, S., Ke, W., Zhu, F., Fan, J., Wang, Q., Liu, Z. and Hartley, W

Copyright, publisher and additional information: this is the author accepted manuscript. The final published version (version of record) is available online via Wiley. This article may be used for non-commercial purposes in accordance with Wiley Terms and Conditions for Self-Archiving. Please refer to any applicable terms of use of the publisher.

DOI link to the version of record on the publisher's site 


\section{Evaluating aggregate stability, surface properties and disintegration}

2 behavior of bauxite residue induced by $\mathrm{Ca} / \mathrm{Na}$

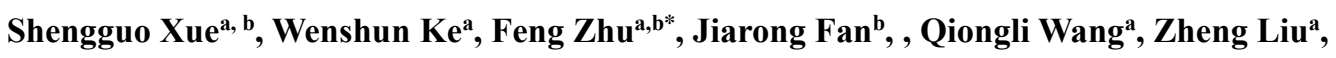
William Hartley

${ }^{a}$ School of Metallurgy and Environment, Central South University, Changsha 410083, PR China

${ }^{\mathrm{b}}$ Chinese National Engineering Research Center for Control and Treatment of Heavy Metal Pollution, Central South University,

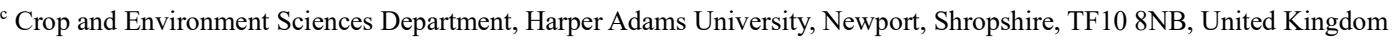

\section{ABSTRACT}

Bauxite residue contains large concentrations of exchangeable $\mathrm{Na}^{+}$, which fragments aggregate structure and limits plant growth. Understanding the potential mechanisms of $\mathrm{Ca} / \mathrm{Na}$ on the formation process of residue aggregates will benefit the screening of appropriate amendments for ecological reconstruction on bauxite residue disposal areas. A method for evaluating aggregate behavior and stability by integration of Le Bissonnais' and laser diffraction measurements, was determined on bauxite residues following $\mathrm{Ca} / \mathrm{Na}$ additions. With increasing $\mathrm{Ca}^{2+}$ addition, mean weight diameter (MWD) increased, indicating improved resistance to dispersion. $\mathrm{Ca}^{2+}$ had a positive effect on flocculation of siltsize microaggregates, whilst disintegration was induced following $\mathrm{Na}+$ addition. Repeated laser diffraction analysis of residue samples circulating in $50 \mathrm{mmol} \mathrm{L}-1$ electrolyte solution $\left(\mathrm{Ca}^{2+} / \mathrm{Na}^{+}\right)$ provided a detailed view of the changes in particle size distribution as aggregates fragmented. The visualized 3D surface map revealed that $\mathrm{Na}^{+}$promotes the disintegration of residue aggregates into finer dispersed particles, whilst $\mathrm{Ca}^{2+}$ protects the microaggregates from fragmenting into smaller particles. Variation in electrochemical properties of aggregate surfaces affected the micro-morphology significantly. The findings provide a new approach to specify pedogenic aggregate behavior of bauxite residue, whilst revealing the effects of $\mathrm{Ca}^{2+} / \mathrm{Na}^{+}$on aggregate stability, surface electrochemical properties and its micromorphology. This new approach will be beneficial to the assessment of soil formation and ecological reconstruction on bauxite residue disposal areas.

\section{HIGHLIGHTS}

1. Aggregate behavior and stability of bauxite residue induced by $\mathrm{Ca} / \mathrm{Na}$ are evaluated.

2. Integration of Le Bissonnais' and laser diffraction methods may effectively reveal aggregate fragmentation.

3. $\mathrm{Ca} / \mathrm{Na}$ addition transformed surface electrochemical properties and micro-morphology of residue aggregates.

4. $\mathrm{Ca}^{2+}$ stimulated aggregate formation, whilst $\mathrm{Na}^{+}$resulted in particles dispersion.

\footnotetext{
* Corresponding author.

E-mail address: zhufeng1990@csu.edu.cn (Feng Zhu); sgxue70@hotmail.com (Shengguo Xue)
} 


\section{Keywords}

2 Bauxite residue, aggregate stability, laser diffraction, surface electrochemistry, soil formation 3 


\section{Introduction}

Bauxite residue, a highly alkaline solid waste, is produced by alumina extraction from bauxite ore by the Bayer process (Santini et al., 2015; Kong et al., 2017). Globally, the inventory of bauxite residue has reached 4.6 Gt, and increased at a rate of $200 \mathrm{Mt}$ per annum (Xue et al., 2019). Disposing and storing these large volumes of residue still remains an increasing environmental risk (Burke et al., 2013). Ecological reconstruction is a promising way forward for the remediation of bauxite residue on a large scale, reducing environmental risks (Xue et al., 2016). Nevertheless, bauxite residue has high salinity (electrical conductivity $\approx 7.4 \mathrm{mS} \mathrm{cm}^{-1}$ ) and alkalinity $(\mathrm{pH} \approx 11.3$, exchangeable sodium percentage $\approx 69 \%$ ), and a fine particle composition (Grafe et al., 2012); these properties result in poor aggregate structure and water holding capacity, which limit plant survival (You et al., 2019).

During the last few decades, a number of studies have focused on the removal of alkalinity and salinity in the residues prior to field rehabilitation. However, it has been increasingly recognized that for successful cover establishment on mine residues, the processes of soil development is critical. Soil aggregates are the basic unit of soil structure and aggregate stability affects the exchange of water, nutrients, gases and heat in soil, as well as the growth and metabolism of animals and microorganisms (Papadopoulos et al., 2009; Tang et al., 2011; Yang et al., 2019). Various methods including wet sieving and Le Bissonnais' (LB's) method have been proposed to characterize aggregate formation due to the complexity of mechanisms on particle aggregation or disintegration (Barthès and Roose, 2002; Almajmaie et al., 2016). Amongst them, Le Bissonnais' method (LB) can simulate different wetting conditions and energies to identify different disaggregation mechanisms. These stability tests do not exhibit the rate of aggregate slaking and the disintegration behavior of the intermediate stages, which may be critical to understanding the response of aggregates to rainfall or other destructive processes. Field et al. (2006) used a combined method of ultrasonication and sieving to destroy soil aggregates and found that aggregate disintegration may be modeled as a first-order reaction to represent aggregate behavior. Kasmerchak et al. (2018) applied repetitive laser diffraction measurements on soil samples to characterize aggregate stability and assess the effects of organic carbon and other chemical properties on soil aggregate behavior. The circulation time of 180 minutes was appropriate to monitor aggregate decomposition following laser diffraction measurement (Mason et al., 2011).

Dispersion or flocculation of aggregates was related to $\mathrm{pH}$, electrolyte and exchangeable base concentrations (Shainberg and Singer, 2011). Curtin et al. (1995) found that Na addition caused clay expansion and disintegration of unstable aggregates. Le Bissonnais et al. (Le bissonnais, 1996a) observed that the cation hydration radius and valence states were important factors which affected aggregate stability; multivalent cations had a strong flocculation effect, whilst monovalent cations had a strong dispersion effect. Furthermore, the interaction force between soil particles was the intrinsic driving force for agglomerate fragmentation ( $\mathrm{Li}$ et al., 2013). Compared to the various external forces in the erosion theory, the internal forces, including electrostatic repulsion between soil particles, were more able to determine soil disaggregation (Hu et al., 2015). According to the DLVO theory of colloidal particle interaction, electrostatic repulsion was controlled by the electric field around the particle, and electric field intensity was determined by the ion interface reaction characteristics (Santos and Yan, 2011). Salt ions in bauxite residue pore water are dominated by $\mathrm{Na}^{+}, \mathrm{K}^{+}, \mathrm{Ca}^{2+}, \mathrm{Mg}^{2+}, \mathrm{Al}(\mathrm{OH})_{4}-\mathrm{SO}_{4}{ }^{2-}, \mathrm{CO}_{3}{ }^{2-}$, and 
$\mathrm{OH}^{-}$(Xu et al., 2018). The high concentrations of soluble ions and exchangeable bases may significantly affect aggregate formation and its stability.

Calcium-contained solid wastes have been applied to ameliorate physical and chemical properties of bauxite residue to support plant growth. However, understanding the potential mechanisms of $\mathrm{Ca}^{2+} / \mathrm{Na}^{+}$on aggregate behavior and its stability for bauxite residue remain scarce. The hypothesis for this study was that following $\mathrm{Ca}^{2+}$ or $\mathrm{Na}^{+}$addition, surface properties and disintegration behavior varied, which changed aggregate size distribution and micro-morphology of residue aggregates. The objectives of this research were to 1) investigate aggregate size distribution and its stability using LB's method following $\mathrm{Ca}^{2+}$ or $\mathrm{Na}^{+}$addition; 2) analyze the effect of $\mathrm{Ca}^{2+}$ or $\mathrm{Na}^{+}$on variations of surface electrochemical properties of residue aggregates; 3) to quantify the disintegration rate of residue aggregates using Laser diffraction analysis.

\section{Materials and methods}

\subsection{Materials}

Fresh bauxite residue was collected to a depth of $20 \mathrm{~cm}$ from a bauxite residue disposal area in Central China. The climate is warm temperate continental monsoon, with an average daily temperature of $12.2-14.8{ }^{\circ} \mathrm{C}$ and mean annual precipitation of $600-700 \mathrm{~mm}$. Samples were subsequently stored in polyethylene bags, returned to the laboratory, air-dried at room temperature for 2 weeks and then passed through a $2 \mathrm{~mm}$ sieve prior to analysis.

\subsection{Aggregate disintegration}

Different concentrations of $\mathrm{NaCl}$ and $\mathrm{CaCl}_{2}$ solutions $(0,5,10,20,50,80,100$, and $200 \mathrm{mmol} / \mathrm{L})$ were selected to determine aggregate disintegration using the modified Le Bissonnais' (LB) method (Le Bissonnais, 1996). This method included three disruptive tests: fast wetting (FW), slow wetting (SW) and wet stirring (WS). For the FW test, $6 \mathrm{~g}$ of $1-2 \mathrm{~mm}$ residue aggregates were quickly immersed in $\mathrm{NaCl}$ or $\mathrm{CaCl}_{2}$ solutions for $10 \mathrm{~min}$. For $\mathrm{SW}, 6 \mathrm{~g}$ of $1-2 \mathrm{~mm}$ residue aggregates were placed on filter paper upon a sponge soaked in ethanol for $30 \mathrm{~min}$. For WS, $6 \mathrm{~g}$ of 1-2mm residue aggregates were gently immersed in ethanol for 10 min prior to immersion in $\mathrm{NaCl}$ or $\mathrm{CaCl}_{2}$ solutions and subsequently shaken in ethanol. The aggregates were then collected by sieving $(1 \mathrm{~mm}, 0.25 \mathrm{~mm}$ and $0.05 \mathrm{~mm})$ and the fractions in each sieve collected, dried at $40{ }^{\circ} \mathrm{C}$ for $24 \mathrm{~h}$ and weighed. Mean weight diameter (MWD) and percentage aggregate destruction (PAD) of the residue samples were calculated using the following equations:

$$
\mathrm{MWD}=\sum_{\mathrm{i}=1}^{\mathrm{n}} \overline{\mathrm{X}_{\mathrm{i}}} \times \mathrm{W}_{\mathrm{i}}
$$

$$
\mathrm{PDA}_{\mathrm{x} / \mathrm{w}}=\frac{\mathrm{W}_{\mathrm{w}}-\mathrm{W}_{\mathrm{x}}}{\mathrm{W}_{\mathrm{w}}} \times 100 \%
$$

Where $\overline{\mathrm{X}_{\mathrm{i}}}$ was the mean diameter over the adjacent sieves $(\mathrm{mm}), \mathrm{W}_{\mathrm{i}}$ was the percentage of residue aggregates in the size range and $n$ was the number of sample sieves. $W_{w}$ was the percentage of $>X \mathrm{~mm}$ residue aggregates after wet sieving using deionized water, and $\mathrm{W}_{\mathrm{x}}$ was the percentage of $>\mathrm{X} \mathrm{mm}$ residue 
Bauxite residue, which was treated by different concentrations of $\mathrm{NaCl}$ or $\mathrm{CaCl}_{2}$ solutions, was separated through a $0.05 \mathrm{~mm}$ sieve and the $<0.05 \mathrm{~mm}$ fractions were dried at $40{ }^{\circ} \mathrm{C}$ for $24 \mathrm{~h}$. The fractions were then added to a $\mathrm{HCl}$ solution $(0.1 \mathrm{~mol} / \mathrm{L})(\mathrm{v}: \mathrm{w}=5: 1)$, oscillated for 5 hours, centrifuged at a speed of $4000 \mathrm{rpm}$ for $5 \mathrm{~min}$, washed several times using deionized water to remove excess $\mathrm{Cl}^{-}$in the suspension and separated to obtain the residues. $5 \mathrm{~g}$ of the residue was added into a $50 \mathrm{ml}$ centrifuge tube and mixed with $10 \mathrm{~mL} \mathrm{Ca}(\mathrm{OH})_{2}$ and $\mathrm{NaOH}$ solution $(0.015 \mathrm{~mol} / \mathrm{L})$. The mixtures were oscillated for 24 hours and subsequently adjusted to $\mathrm{pH} 7$ using $\mathrm{HCl}$. The concentrations of $\mathrm{Ca}^{2+}$ and $\mathrm{Na}^{+}$in the supernatant were then determined using ICP-MS (Hu et al., 2015).

The surface potential $(\varphi(V))$, surface electric field intensity $(E)$, and specific surface area (S) of residue aggregates were calculated by the following equations (Li et al., 2011):

$$
\varphi=\frac{2 \mathrm{RT}}{\left(2 \beta_{\mathrm{Ca}}-\beta_{\mathrm{Na}}\right) \mathrm{F}} \ln \frac{\mathrm{a}_{\mathrm{Ca}}^{0} \mathrm{~N}_{\mathrm{Na}}}{\mathrm{a}_{\mathrm{Na}}^{0} \mathrm{~N}_{\mathrm{Ca}}}
$$$$
E=\frac{4 \pi}{\varepsilon} \sigma
$$

$$
\mathrm{S}=\frac{\mathrm{N}_{\mathrm{Na}} \mathrm{k}}{\mathrm{ma}_{\mathrm{Na}}^{0}} \mathrm{e}^{\frac{\mathrm{F} \varphi \beta_{\mathrm{Na}}}{2 \mathrm{RT}}}=\frac{N_{\mathrm{Ca}} \mathrm{k}}{\mathrm{ma}_{\mathrm{Ca}}^{0}} \mathrm{e}^{\frac{\mathrm{F} \varphi \beta_{\mathrm{Ca}}}{2 \mathrm{RT}}}
$$

$$
\mathrm{K}=\sqrt{\frac{8 \pi \mathrm{F}^{2}\left(\frac{1}{2} \sum \mathrm{a}_{\mathrm{i}}^{0} \mathrm{Z}_{\mathrm{i}}^{2}\right)}{\varepsilon \mathrm{RT}}}
$$

$$
\mathrm{a}_{\mathrm{i}}^{0}=\gamma_{\mathrm{i}} \mathrm{c}_{\mathrm{i}}^{0}
$$

$\log \gamma_{\mathrm{i}}=0.512 \mathrm{Z}_{\mathrm{i}}^{2}\left(\frac{\mathrm{I}^{1 / 2}}{\mathrm{I}+\mathrm{I}^{1 / 2}}-0.3 \mathrm{I}\right)$

$$
\beta_{\mathrm{Ca}}=0.0213 \ln \left(\mathrm{I}^{0.5}\right)+1.2331
$$

$$
\beta_{\mathrm{Na}}=0.0213 \ln \left(\mathrm{I}^{0.5}\right)+0.7669
$$$$
\mathrm{m}=0.5259 \ln \left(\mathrm{c}_{\mathrm{Na}}^{0} / \mathrm{c}_{\mathrm{Ca}}^{0}\right)+1.992
$$

Where $\mathrm{R}(\mathrm{J} / \mathrm{K} \mathrm{mol})$ is a universal gas constant, $\mathrm{T}(\mathrm{K})$ the system temperature, $\mathrm{F}(\mathrm{C} / \mathrm{mol})$ the Faraday constant, $\mathrm{k}(1 / \mathrm{dm})$ the Debye-Huckel constant, and $\varepsilon$ the dielectric constant of water. I (mol/L) was the ionic strength, $\mathrm{a}_{\mathrm{Na}}^{0}$ and $\mathrm{a}_{\mathrm{Ca}}^{0}(\mathrm{~mol} / \mathrm{L})$ respectively for the activity of $\mathrm{Na}^{+}$and $\mathrm{Ca}^{2+}$ in the solution at equilibrium, $\mathrm{N}_{\mathrm{Na}}$ and $\mathrm{N}_{\mathrm{Ca}}(\mathrm{mol})$ are the adsorption capacities of $\mathrm{Na}^{+}$and $\mathrm{Ca}^{2+}$ in the residue, respectively. $c_{\mathrm{Na}}^{0}$ and $c_{\mathrm{Ca}}^{0}(\mathrm{~mol} / \mathrm{L})$ were concentration of $\mathrm{Na}^{+}$and $\mathrm{Ca}^{2+}$ in the solution at equilibrium. $\beta_{\mathrm{Na}}$ and $\beta_{\mathrm{Ca}}$ were correction coefficients for correcting the effective charge amount of $\mathrm{Na}^{+}$and $\mathrm{Ca}^{2+}$, respectively.

\section{5}

\subsection{Analysis of aggregate behavior}

In order to investigate the effect of $\mathrm{Ca}$ or $\mathrm{Na}$ on residue aggregation, residue samples which were treated by $50 \mathrm{mmol} / \mathrm{L} \mathrm{NaCl}$ and $\mathrm{CaCl}_{2}$ solutions were selected to determine aggregate behavior using a

108 laser particle analyzer (Malvern Mastersizer 2000). The analytical method is described by Mason et al. 109 (2011) and Kasmerchar et al. (2018) as follows: selected aggregate samples were added continuously 
into a beaker containing $500 \mathrm{ml}$ of deionized water or $50 \mathrm{mmol} / \mathrm{L} \mathrm{CaCl} / 2 / \mathrm{NaCl}$ solutions until the solution

111 obscuration reached 5\%-10\%. Then the particle size distributions (PSD) of residue aggregates can be 112 measured through a laser diffraction analysis cell. The PSD was measured every two minutes for the first

11320 minutes and every ten minutes for the last 160 minutes. During the 180 -minute measurement period, 114 the solution was constantly stirred at a constant speed of $2000 \mathrm{rpm}$ and pumped to the laser diffraction 115 analysis cell. According to the methodology of Mason et al. (Mason et al., 2011), variations of $>250 \mu \mathrm{m}$ 116 and $<20 \mu \mathrm{m}$ fractions were determined and fitted using the following equations:

$$
\begin{aligned}
& \%>250 \mu \mathrm{m}=\mathrm{A}_{1} \times \exp \left(-\mathrm{K}_{1} \mathrm{~T}\right)+\mathrm{Cl} \\
& \%<20 \mu \mathrm{m}=\mathrm{A}_{2} *\left[1-\exp \left(-\mathrm{K}_{2} \mathrm{~T}\right)\right]+\mathrm{C} 2
\end{aligned}
$$

where $K_{1}$ and $K_{2}$ are rate constants, $T$ is circulation time, $A_{1}$ and $A_{2}$ are rate coefficients, $C_{1}$ is the final percentage of $>250 \mu \mathrm{m}$ fractions, and $\mathrm{C}_{2}$ represents the initial percentage of $<20 \mu \mathrm{m}$ fractions in the residue aggregates. The parameters $\mathrm{A}_{1}, \mathrm{~A}_{2}, \mathrm{k}_{1}, \mathrm{k}_{2}, \mathrm{C}_{1}$ and $\mathrm{C}_{2}$ were determined using the obtained PSD data to fit Eqs. (15-16) and minimize the quadratic sum of residuals from models (Field and Minasny, 123 1999).

\subsection{Morphological analysis}

SEM-EDS of $<0.05 \mathrm{~mm}$ residue aggregates from the three different treatments (DI, and $50 \mathrm{mmol} / \mathrm{L}$ $\mathrm{NaCl} / \mathrm{CaCl}_{2}$ ) were scanned using a scanning electron microscope (ESEM, Quanta-200). The samples were sprayed with Au prior to scanning using a GSED field emission gun.

\subsection{Statistical methods}

All data were analyzed in Excel 2010, IBM $®$ SPSS $®$ Statistics version.21, OriginLab ${ }^{\circledR}$ Origin $®$ r. 9.0. and MATLAB R2017b. All figures and lines representing first-order models were constructed by

131 Origin 9.0. The three-dimensional surface map of the particle size distribution of bauxite residue 132 aggregates after different ion treatments was draw by MATLAB R2017b.

\section{3. Results and discussion}

\section{$1343.1 \mathrm{Effect}$ of $\mathrm{Ca}^{2+} / \mathrm{Na}^{+}$on aggregate size distribution}

Aggregate size distribution of bauxite residue following different treatments is presented in Fig. 1. For the FW test (simulating the slaking process), $<0.05 \mathrm{~mm}$ aggregates were the major fraction. With

$137 \mathrm{CaCl}_{2}$ treatment, the proportion of $2-0.25 \mathrm{~mm}$ aggregates ranged from $45.92 \%$ to $52.02 \%$, which were 138 higher than in untreated residues. With increasing $\mathrm{Na}^{+}$concentration, the proportion of $<0.05 \mathrm{~mm}$ 139 microaggregates increased from $42.5 \%$ to $54.4 \%$. For the SW test (simulating differential clay swelling 140 processes) and the WS test (simulating the mechanism of breakdown processes), 2-1 mm aggregates 141 were the major fractions. With $\mathrm{CaCl}_{2}$ treatment, the proportions of 2-1 mm aggregates increased from $60.9 \%$ to $62.2 \%$ and $69.8 \%$ for the SW and WS test, respectively.

$143 \mathrm{Ca}^{2+}$ and $\mathrm{Na}^{+}$are the critical cations in bauxite residue (Xue et al., 2019), and their concentrations 144 can significantly affect aggregation processes. Aggregate size distribution from the modified LB method 145 revealed that Ca may increase the proportion of water-stable aggregates $(>0.25 \mathrm{~mm})$, whilst $\mathrm{Na}^{+}$resulted 
in disaggregation of larger sized aggregates.
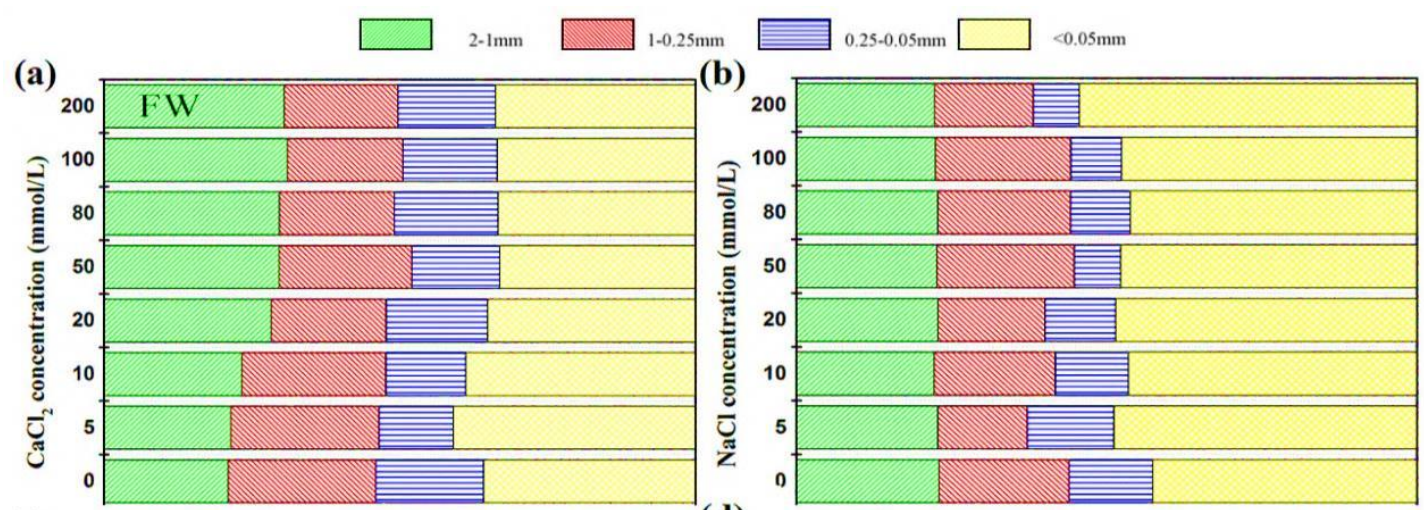

(c)
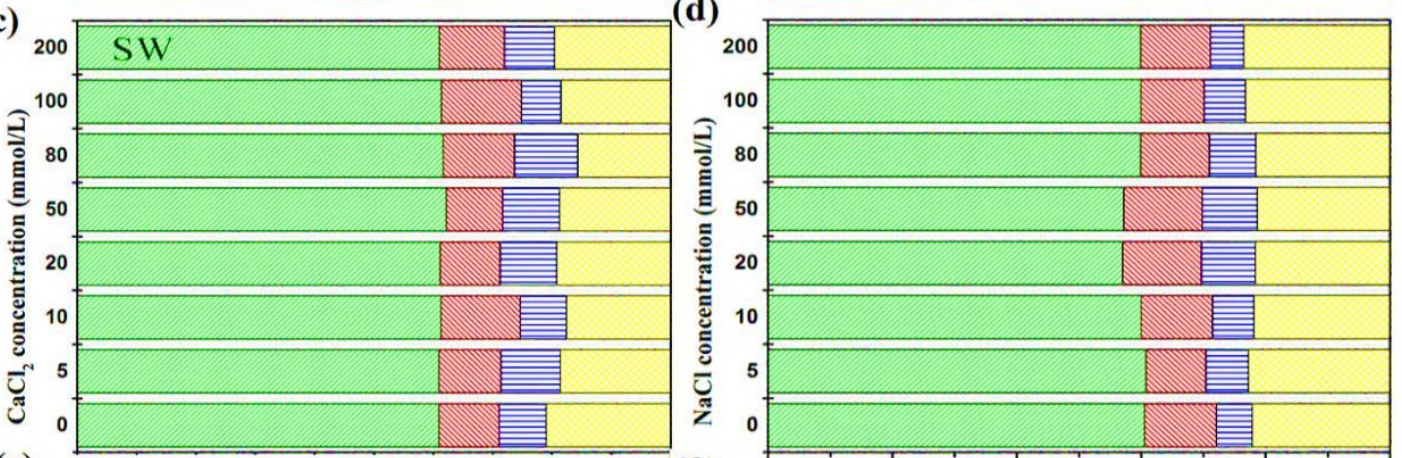

(e)

(f)
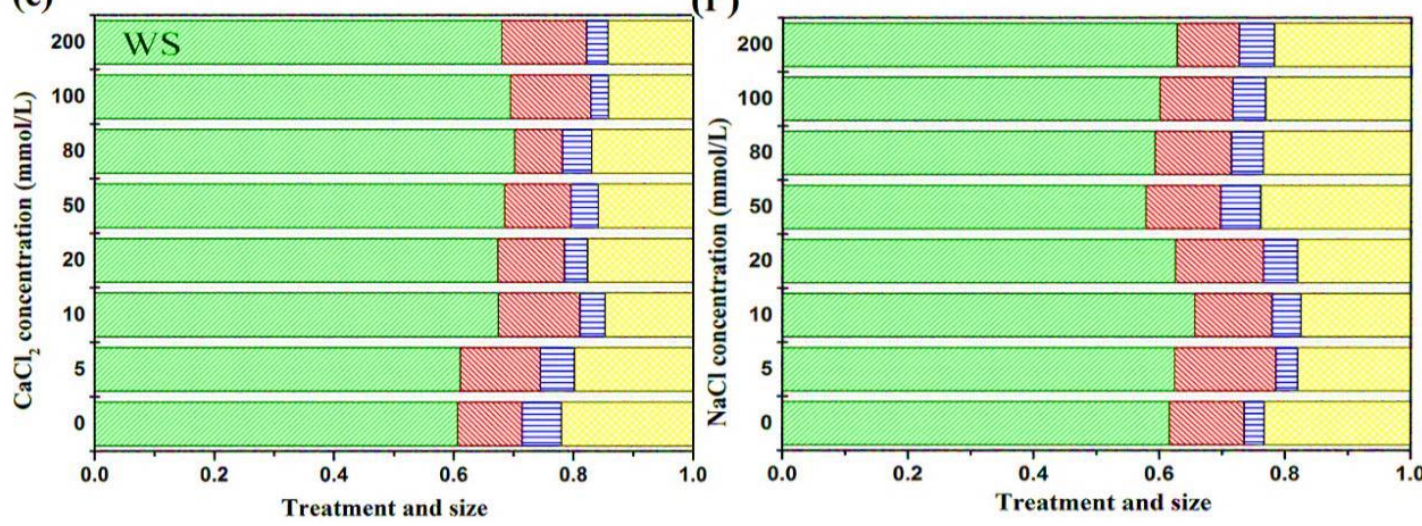

Fig. 1 Effect of $\mathrm{Ca}^{2+} / \mathrm{Na}^{+}$on aggregate fraction distribution of the treated residues from the modified Le Bissonnais' method: a \&

b) FW test; c \& d) SW test; e \& f) WS test.

MWD is a characteristic indicator used to evaluate aggregate stability and a large MWD indicates improved aggregate stability (Mbagwu and Auerswald, 1999; You et al., 2018; Cui et al., 2019). Variation in MWD following $\mathrm{NaCl}$ and $\mathrm{CaCl}_{2}$ additions are presented in Fig. 2. For the three different tests, $\mathrm{CaCl}_{2}$ addition increased MWD due to the accumulation of larger sized fractions. With increasing $\mathrm{NaCl}$ concentration, MWD decreased, although this did fluctuate. When the electrolyte concentration was 50 $\mathrm{mmol} / \mathrm{L}, \mathrm{MWD}$ of $\mathrm{CaCl}_{2}$ treated samples reached a relatively high value, whilst a relatively low value occurred for $\mathrm{NaCl}$ treatments.

Electrolyte concentration, and cation valence state, significantly affected the formation of stable aggregates, especially for flocculation and dispersion of clay-size particles (Olis, 1989). Multivalent cations, including $\mathrm{Ca}^{2+}, \mathrm{Fe}^{3+}$ and $\mathrm{Al}^{3+}$, all formed ion bridges, compressing the thickness of the electric double layer, and promoting particle flocculation (Jiang et al., 2012). In this study, addition of $\mathrm{CaCl}_{2}$ 
accumulated the proportion of macroaggregates $(>0.25 \mathrm{~mm})$, improved aggregate stability and enhanced erosion resistance of residues. The residue contained a large amount of $\mathrm{Na}^{+}$, which resulted in particle dispersion and poor physical condition. Results demonstrated that $\mathrm{NaCl}$ increased the proportion of $<0.05$ $\mathrm{mm}$ microaggregates whilst reducing the stability of residue aggregates. Monovalent cations disperse aggregates whilst multivalent cations promote flocculation. Le Bissonnais ( Le Bissonnais, Y., 2016.) considered that multivalent cations may effectively promote flocculation of aggregates, whilst monovalent cations have a strong dispersive effect. An excess of $\mathrm{Na}^{+}$may weaken covalent interaction between organic molecules and clay-sized particles, which may lead to aggregate dispersion. Zhu et al., (2017) observed that $\mathrm{Na}^{+}$was negatively correlated with aggregate stability in bauxite residue following amendment addition, which was consistent with the results of this study.
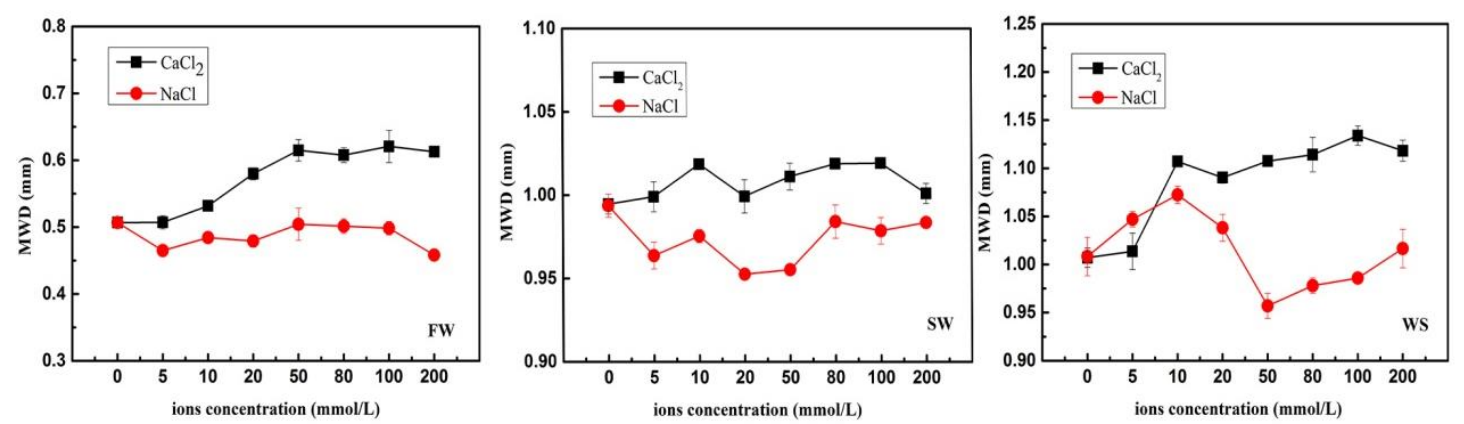

Fig.2 Effect of $\mathrm{Ca}^{2+} / \mathrm{Na}^{+}$on aggregate stability of bauxite residue. a) FW test; b) SW test; c) WS test.

The percentage of aggregate destruction (PADx), which is the fraction of $>x \mathrm{~mm}$ aggregates after wet sieving, may be used to evaluate variation in water-stable aggregates (GUBER et al., 2005). A positive value for PADx indicates dispersion, whilst a negative value indicates aggregation. The larger the absolute value of PADx, the stronger the corresponding effects. Variation in PADx in the treated residues is presented in Fig. 3. For FW treatments, the absolute values of $\mathrm{PAD}_{0.25}$ were 3.71\%, 3.80\%, $13.2 \%, 5.68 \%, 12.52 \%$, and $10.02 \%$ when the concentration of $\mathrm{CaCl}_{2}$ solution was $10,20,50,80,100$, and $200 \mathrm{mmol} / \mathrm{L}$, respectively. This indicated that $\mathrm{CaCl}_{2}$ had a significant protective effect on $>0.25 \mathrm{~mm}$ residue aggregates. Compared to $\mathrm{PAD}_{0.25}$, the absolute value of $\mathrm{PAD}_{0.05}$ was smaller, which indicated that $\mathrm{CaCl}_{2}$ had a stronger aggregation effect on $>0.25 \mathrm{~mm}$ aggregates. The values of $\mathrm{PAD}_{0.25}$ and $\mathrm{PAD}_{0.05}$ for

$182 \mathrm{NaCl}$ treated residues were positive, and significantly higher than those following $\mathrm{CaCl}_{2}$ treatment. This demonstrates that $\mathrm{NaCl}$ had an clear dispersive effect on residue aggregates. For FW, SW or WS treatments, the absolute values of $\mathrm{PAD}_{0.25}$ and $\mathrm{PAD}_{0.05}$ balance with the concentrations of $\mathrm{NaCl}$ or $\mathrm{CaCl}_{2}$ ranging from $50 \mathrm{mmol} / \mathrm{L}$ to $80 \mathrm{mmol} / \mathrm{L}$, but then decrease gradually. Zhu et al., (2016) observed that with the removal of salinity, clay-sized aggregates increased and microaggregate stability decreased in bauxite residues. Soluble salts may exist as a solid state and bind fine particles to improve aggregation (Bronick and Lal, 2005). Amézketa (1999), stated that low electrolyte concentrations and high SAR (Sodium Adsorption Ratio) values produced clay dispersion and swelling. With the increase in soluble ions, electrolyte concentrations of the residue solutions increased, which may have resulted in particle aggregation. Furthermore, $\mathrm{Na}^{+}$addition increased the SAR values which may have led to a loss in aggregate structure. Therefore, following $\mathrm{NaCl}$ or $\mathrm{CaCl}_{2}$ additions, the values of $\mathrm{PAD}_{0.25}$ and $\mathrm{PAD}_{0.05}$ varied in volatility. 

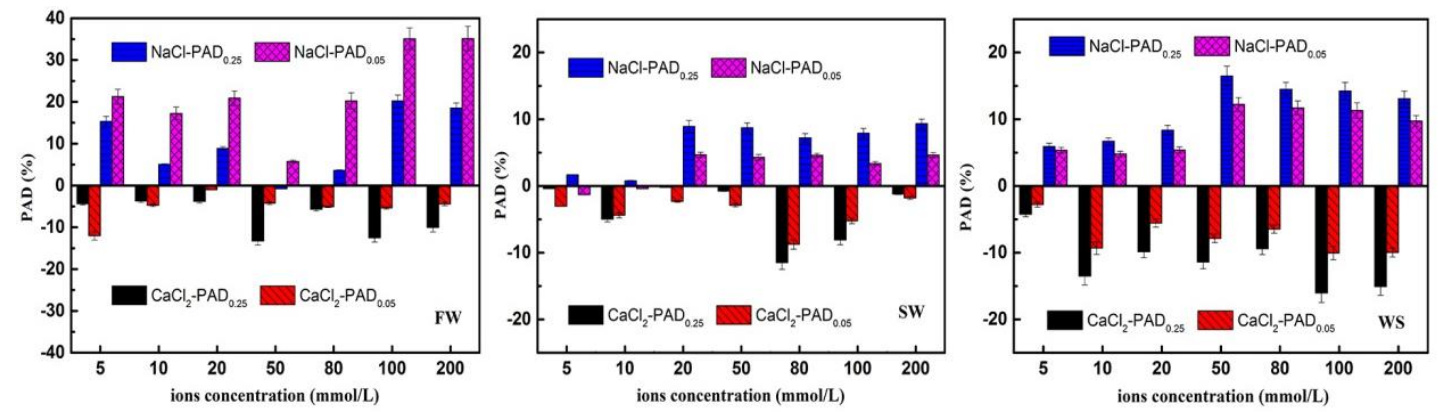

Fig. 3 Effect of $\mathrm{Ca}^{2+} / \mathrm{Na}^{+}$on the percentage of aggregate destruction of bauxite residues. a) FW test; b) SW test; c) WS test.

\subsection{Effect of $\mathrm{Ca}^{2+} / \mathrm{Na}^{+}$on aggregate surface properties}

Variations in $\mathrm{pH}$ of bauxite residue microaggregates $(<0.05 \mathrm{~mm})$ following the different electrolyte treatments are presented in Table 1. $\mathrm{pH}$ declined gradually with less than $20 \mathrm{mmol} / \mathrm{L} \mathrm{Ca}^{2+}$, but decreased sharply to approximately 8 when $\mathrm{Ca}^{2+}$ exceeded $50 \mathrm{mmol} / \mathrm{L}$. $\mathrm{Ca}^{2+}$ may bind to alkaline anions (e.g. $\mathrm{CO}_{3}{ }^{2-}$ ) in the residues to form insoluble calcium-containing minerals to decrease the $\mathrm{pH}$ of the solution. With addition of $\mathrm{Na}^{+}, \mathrm{pH}$ did not change. $\mathrm{pH}$ varied the composition of cations in solution, which may affect electrochemical properties (e.g. charge density, surface potential, surface charge) of the surface of residue aggregates. Calcium reduced the $\mathrm{OH}^{-}$concentration and the negative surface charge on residue particles, which may reduce particle repulsion and improve aggregation.

Table. 1 Effect of $\mathrm{Ca}^{2+} / \mathrm{Na}^{+}$on $\mathrm{pH}$ of bauxite residue

\begin{tabular}{ccccccccc}
\hline & \multicolumn{7}{c}{ Electrolyte concentration (mmol/L) } \\
\cline { 2 - 8 } & 0 & 5 & 10 & 20 & 50 & 80 & 100 & 200 \\
\hline $\mathrm{Na}^{+}$ & $11.18 \pm 0.21$ & $10.89 \pm 0.13$ & $10.94 \pm 0.12$ & $10.69 \pm 0.22$ & $10.60 \pm 0.30$ & $10.66 \pm 0.20$ & $10.64 \pm 0.19$ & $10.67 \pm 0.22$ \\
$\mathrm{Ca}^{2+}$ & $11.13 \pm 0.31$ & $10.82 \pm 0.15$ & $10.65 \pm 0.40$ & $10.16 \pm 0.21$ & $8.21 \pm 0.32$ & $7.64 \pm 0.13$ & $7.72 \pm 0.34$ & $7.79 \pm 0.10$ \\
\hline
\end{tabular}

The composition of ions significantly varied soil surface properties including electric field intensity, surface potential, and specific surface area of aggregates. Effects of $\mathrm{Ca}^{2+} / \mathrm{Na}^{+}$on surface properties of $<0.05 \mathrm{~mm}$ residue aggregates are presented in Fig. 4. With an increase in electrolyte concentration, both electric field intensity and surface potential decreased. Parsons et al., (2011) observed that the increased electrolyte concentration had a strong compression effect, reducing the electric double layer of colloidal particles, which may improve the counter ions to shield the surface charge and decrease the surface

212 potential of microaggregates. $\mathrm{Ca}^{2+}$ is a divalent ion, which may produce a stronger compression effect 213 on the electric double layer than that of $\mathrm{Na}^{+}$(Pashley, 1981). Therefore, the surface potential of 214 microaggregates following $\mathrm{Ca}^{2+}$ addition was smaller. With an increase in $\mathrm{Ca}^{2+}$ concentration, the specific 215 surface area of microaggregates decreased from $6.12 \mathrm{~m}^{2} / \mathrm{g}$ to $0.68 \mathrm{~m}^{2} / \mathrm{g}$. Furthermore, the specific 216 surface area increased to $13.3 \mathrm{~m}^{2} / \mathrm{g}$ following $\mathrm{Na}^{+}$addition. This was because flocculation or dispersion 217 of particles determined the changes of specific surface area. $\mathrm{Ca}^{2+}$ promoted the stability of 218 microaggregates, whilst $\mathrm{Na}^{+}$resulted in particle dispersion 

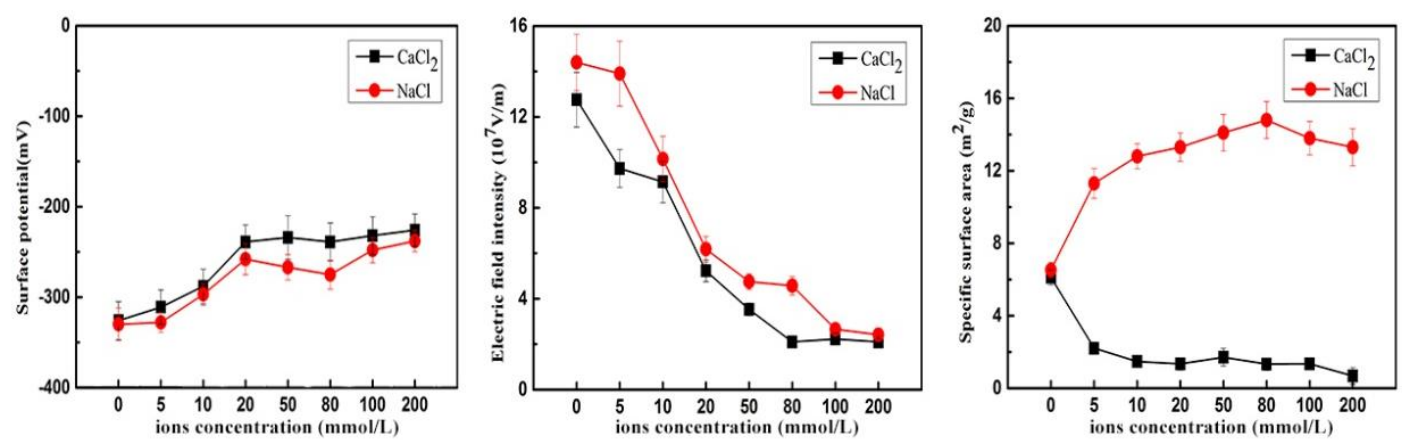

Fig.4 Effect of $\mathrm{Ca}^{2+} / \mathrm{Na}^{+}$on surface properties of $<0.05 \mathrm{~mm}$ residue aggregates.

\subsection{Effect of $\mathrm{Ca}^{2+} / \mathrm{Na}^{+}$on pedogenic aggregate behavior}

Aggregate behavior results are depicted as either continuous surfaces plots which portray changes in the overall size distribution over time (Fig. 5A-C), or in the proportion of individual size fractions (Fig. $5 \mathrm{a}-\mathrm{c})$. This represents a detailed view of aggregate disintegration and hydrodynamic behavior in deionized water and other solution electrolytes. For the different treatments, the fastest disintegration rate in the first 20 minutes decreased as follows: $\mathrm{Na}>\mathrm{DI}>\mathrm{Ca}$ (Fig. 5A-C). PSD of the three samples varied in the first 60 minutes and then approached a stable state. Variation in PSD in the salt solutions was different, which indicated that residue aggregates exhibited diverse disintegration and hydrodynamic behaviors under the effects of different ions.

For $\mathrm{NaCl}$ treated residues, the initial PSD peak disintegrated following a 30-minute circulation, but then stabilized and persisted during the remaining circulation time (Fig. 5A). During circulation, a peak of 20-50 $\mu \mathrm{m}$ appeared, revealing that fractions $>250 \mu \mathrm{m}$ disintegrated into $20-50 \mu \mathrm{m}$ smaller particles.

For the control samples, the initial flat peak of PSD occurred in the range of 2-250 $\mu \mathrm{m}$ after a 20 -min circulation period (Fig. 5B). This indicated that large size aggregates may disintegrate into microaggregates in the presence of $\mathrm{Na}^{+}$. For $\mathrm{CaCl}_{2}$ treated residues, the initial peak of PSD collapsed at a circulation time of 40 minutes, and the peak height remained at approximately $1.5 \%$ at the end of the circulation period (Fig. 5C).

Tisdall and Oades, (1982) proposed a hierarchical model according to the soil aggregate formation process; principally, primary particles $(<20 \mu \mathrm{m})$ and the cements bond together to form microaggregates (20-250 $\mu \mathrm{m})$, and thereby form larger aggregates $(>250 \mu \mathrm{m})$. Variations between the size fractions $(>250$ $\mu \mathrm{m}, 100-250 \mu \mathrm{m}, 20-100 \mu \mathrm{m}$ and $<20 \mu \mathrm{m})$ over time and the aggregate disintegration model by the firstorder rate equation are presented in Fig. 2a-c. In most cases, the first-order rate equation can fit the trend of PSD, which provided details of aggregation behavior that could not be clearly expressed in the threedimensional surface map. The first-order rate equation parameters for different partial particles in different treatments are presented in Table 2. After circulation for 180-minutes, variations in $\mathrm{C}_{1}$ and $\mathrm{C}_{2}$ values revealed that $\mathrm{Ca}^{2+}$ addition increased the water-stable aggregate content, whilst $\mathrm{Na}^{+}$promoted dispersion of residue aggregates. The $>250 \mu \mathrm{m}$ aggregate fraction mainly included macro-aggregates, medium to coarse sand grains, and larger coarse mineral fragments. This fraction dispersed rapidly, with at least half of the decline occurring in the first 20 minutes and almost all of it within approximately 60 minutes (Fig. 5a-c). The 100-250 $\mu \mathrm{m}$ aggregate fraction included medium sand grains and large size micro-aggregates. Following the first 10 minutes of circulation, the 100-250 $\mu \mathrm{m}$ aggregate fraction fell 
sharply, but then slowly declined. This reflected that the 100-250 $\mu \mathrm{m}$ aggregates were rapidly disaggregated into $<100 \mu \mathrm{m}$ aggregates, followed by slow disintegration of the latter into primary mineral particles and smaller microaggregates. The short-term fluctuation of $>250 \mu \mathrm{m}$ and 100-250 $\mu \mathrm{m}$ aggregates was probably due to a relatively small number of sand-sized particles, and aggregates or coarse organic fractions that could not be acquired homogeneously by the particle size analyzer pump, thereby producing substantial fluctuations. Furthermore, the 20-100 $\mu \mathrm{m}$ aggregates varied monotonically, representing a slightly decrease in microaggregates with small particle size with long-term circulation.

This indicates that $>100 \mu \mathrm{m}$ fractions disaggregate into finer particles under the action of hydraulic power. In contrast, trends for $<20 \mu \mathrm{m}$ aggregates increased rapidly with almost all within 60 minutes, clearly reflecting disintegration of microaggregates. The $<20 \mu \mathrm{m}$ fractions included clay-size particles, humic materials and other cements. The results demonstrated that residue aggregates with a large size mainly disaggregated into $<20 \mu \mathrm{m}$ fractions according to the trends of these fractions with circulation time.
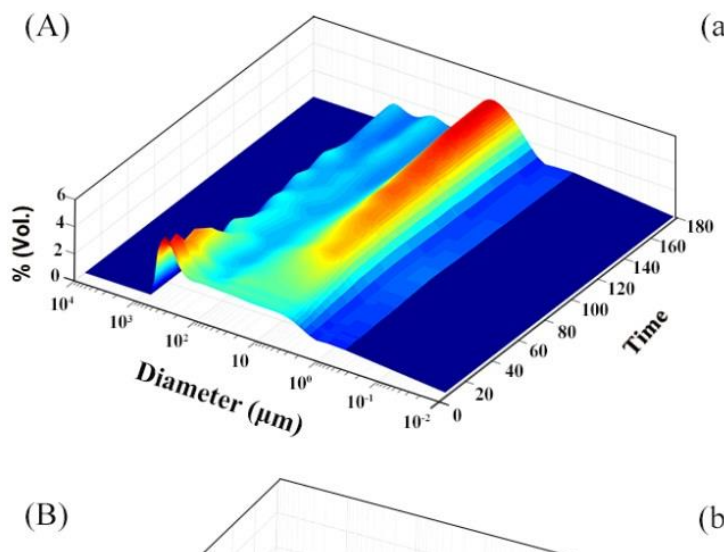

(B)
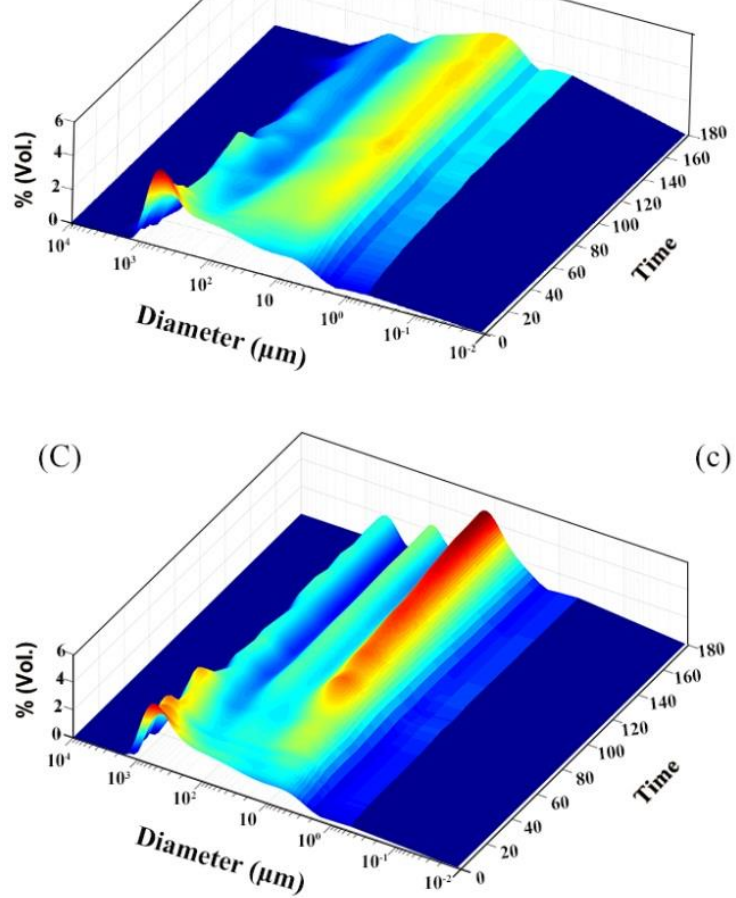

(b)

c)

Fig. 5 Surfaces representing change in particle size distribution with time, for bauxite residue after $\mathrm{Ca}^{2+} / \mathrm{Na}^{+}$treatment. Height of
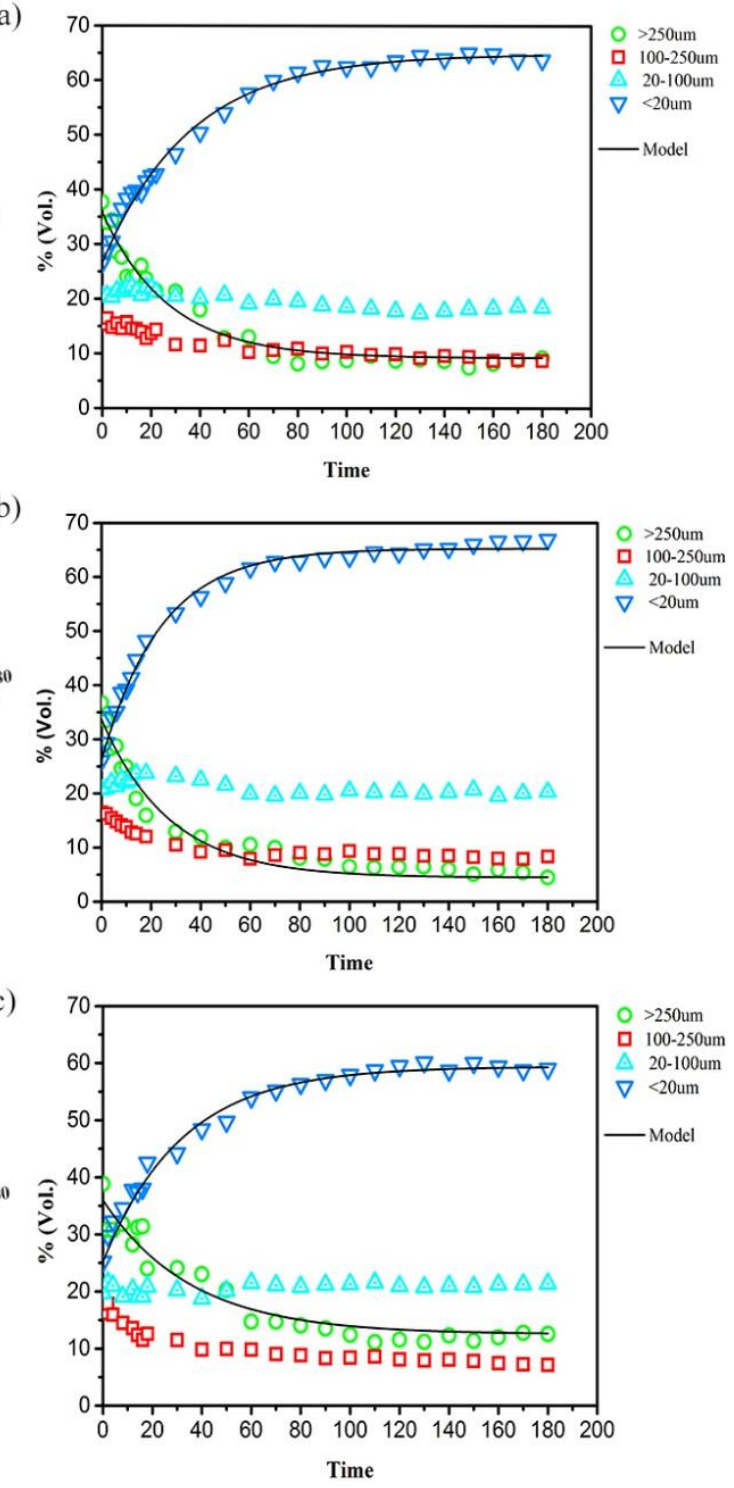

surface represents volumetric percentage in each particle diameter class, as it changes over time from 0 to 180 min of circulation. 
Variations for multiple size fractions over the course of the experiment, lines represent first-order models fit to decrease of $>250$

$\mu \mathrm{m}$ or increase of $<20 \mu \mathrm{m}$ fraction. A \& a) control, B \& b), $\mathrm{Na}^{+}$and $\left.\mathrm{C} \& \mathrm{c}\right) \mathrm{Ca}^{2+}$.

The results showed that the method described by Mason et al., (2011) and Kasmerchak et al. (2018)

270 could evaluate aggregate behavior of bauxite residue following $\mathrm{Ca}^{2+}$ or $\mathrm{Na}^{+}$treatments. Three-

271 Dimensional surfaces and variations of specific particles intuitively reflect aggregate behavior during

272180 minutes of circulation. Zeng et al., (2011) investigated the effects of monovalent and divalent salt-

273 based ions on soil aggregation, and observed that the $>0.25 \mathrm{~mm}$ macroaggregates contained higher

274 contents of salt ions, especially for multivalent metal ions than those in microaggregates. The increase in

275 monovalent ions and the leaching of divalent ions may lead to the dispersion of aggregates and the

276 deterioration of soil quality. All treatments revealed that the majority of $>0.25 \mathrm{~mm}$ aggregates

277 disintegrated and the small sized aggregates persisted after circulation. The presence of water molecules

278 swelling the mineral crystal lattice, may have stimulated clay dispersion (Pashley and Israelachvili, 1984).

279 Furthermore, residue aggregates disintegrated more rapidly in the presence of $\mathrm{Na}^{+}$, whilst $\mathrm{Ca}^{2+}$ in solution

280 could form ion bridges in the electric double layer and reduce the expansion of water molecules.

281 Table 2. Parameters used to model aggregate breakdown as a first-order process

\begin{tabular}{|c|c|c|c|c|c|c|c|c|c|c|c|}
\hline treatment & $\mathrm{A}_{1}$ & $\mathrm{~K}_{1}$ & $\mathrm{C}_{1}$ & $\mathrm{R}_{1}^{2}$ & $\mathrm{~A}_{2}$ & $\mathrm{~K}_{2}$ & $\mathrm{C}_{2}$ & $\mathrm{R}_{2}^{2}$ & $\mathrm{a}$ & $\mathrm{b}$ & $\mathrm{c}$ \\
\hline control & 26.6140 & 0.0371 & 9.2105 & 0.9669 & 38.2703 & 0.0278 & 26.5515 & 0.9922 & 25.6455 & 37.2222 & 0.6890 \\
\hline $\mathrm{Na}^{+}$ & 29.2771 & 0.0365 & 4.4581 & 0.9630 & 39.2036 & 0.0418 & 26.0496 & 0.9938 & 28.2280 & 37.6005 & 0.7507 \\
\hline $\mathrm{Ca}^{2+}$ & 23.4984 & 0.0280 & 12.5148 & 0.9406 & 34.1733 & 0.0313 & 25.2214 & 0.9842 & 22.8493 & 33.1199 & 0.6899 \\
\hline
\end{tabular}

\section{$283 \quad 3.4$ Effect of $\mathrm{Ca}^{2+} / \mathrm{Na}^{+}$on aggregate micro-morphology}

284 The presence of $\mathrm{Ca}$ or $\mathrm{Na}$ changed the surface properties, affected aggregate behavior, and varied 285 aggregate size distribution of bauxite residue. SEM-EDS analysis was used to determine changes in 286 micro-morphology and elemental distribution of $<0.05 \mathrm{~mm}$ residue aggregates. SEM images of the three 287 treatments $\left(\mathrm{Na}^{+}, \mathrm{DI}\right.$, and $\left.\mathrm{Ca}^{2+}\right)$ are presented in Fig. 6. Scanning electron microscope imaging of control 288 samples revealed that $0.2-1 \mu \mathrm{m}$ particles were the major fraction present. Control residue 289 microaggregates had sheet- or prismatic-like structures and there were relatively few fine fragments.

290 With addition of $\mathrm{NaCl}$, microaggregates sizes became smaller and the fine fragments increased. The 291 major fractions of Ca-treated microaggregates were $0.5-1 \mu \mathrm{m}$ particles and their structure was converted 292 from a sheet-like to prismatic-like form. The variation in residue micro-morphology directly reflected 293 the input of $\mathrm{Ca}^{2+}$, by revealing that it could improve aggregate structure and enhance aggregate stability 294 of residues. Similarly, using a combination methods including SEM-EDS and synchrotron-based Xray micro-computed tomography, gypsum has been shown to improve particle size of residue aggregates, enhancing the number of large pore spaces (Xue et al., 2019). Multivalent ions such as $\mathrm{Ca}^{2+}$ may bind

298 precipitates to form carbonate coatings and bind mineral particles together to inhibit clay dispersion 299 (Jiang et al., 2012). Kong et al., (2017) investigated acid transformation of bauxite residue, they found 300 that gypsum addition promoted the leaching of sodium ions and accelerated the $0.2-1 \mu \mathrm{m}$ particle fraction 301 in 2-5 $\mu \mathrm{m}$ aggregates due to calcium's positive effect.

302 According to EDS analysis, $\mathrm{Na}, \mathrm{Ca}, \mathrm{Al}$ and $\mathrm{Fe}$ on the surfaces of residue aggregates were the major 
chemical elements. The mass fractions of $\mathrm{Na}, \mathrm{Ca}, \mathrm{Al}$ and $\mathrm{Fe}$ on the surfaces accounted for $4.45 \%, 7.33 \%$,

$30427.47 \%$, and $25.49 \%$, respectively. Addition of $\mathrm{CaCl}_{2}$ significantly accumulated $\mathrm{Ca}$ whilst reducing $\mathrm{Na}$.

305 This indicated that $\mathrm{Ca}^{2+}$ could replace exchangeable $\mathrm{Na}^{+}$on the surface of the particles and the extra $\mathrm{Na}^{+}$

306 would be leached out in solution. $\mathrm{Ca}^{2+}$ on the aggregate surface may then improve aggregate structure 307 and micro- morphology of the residues.
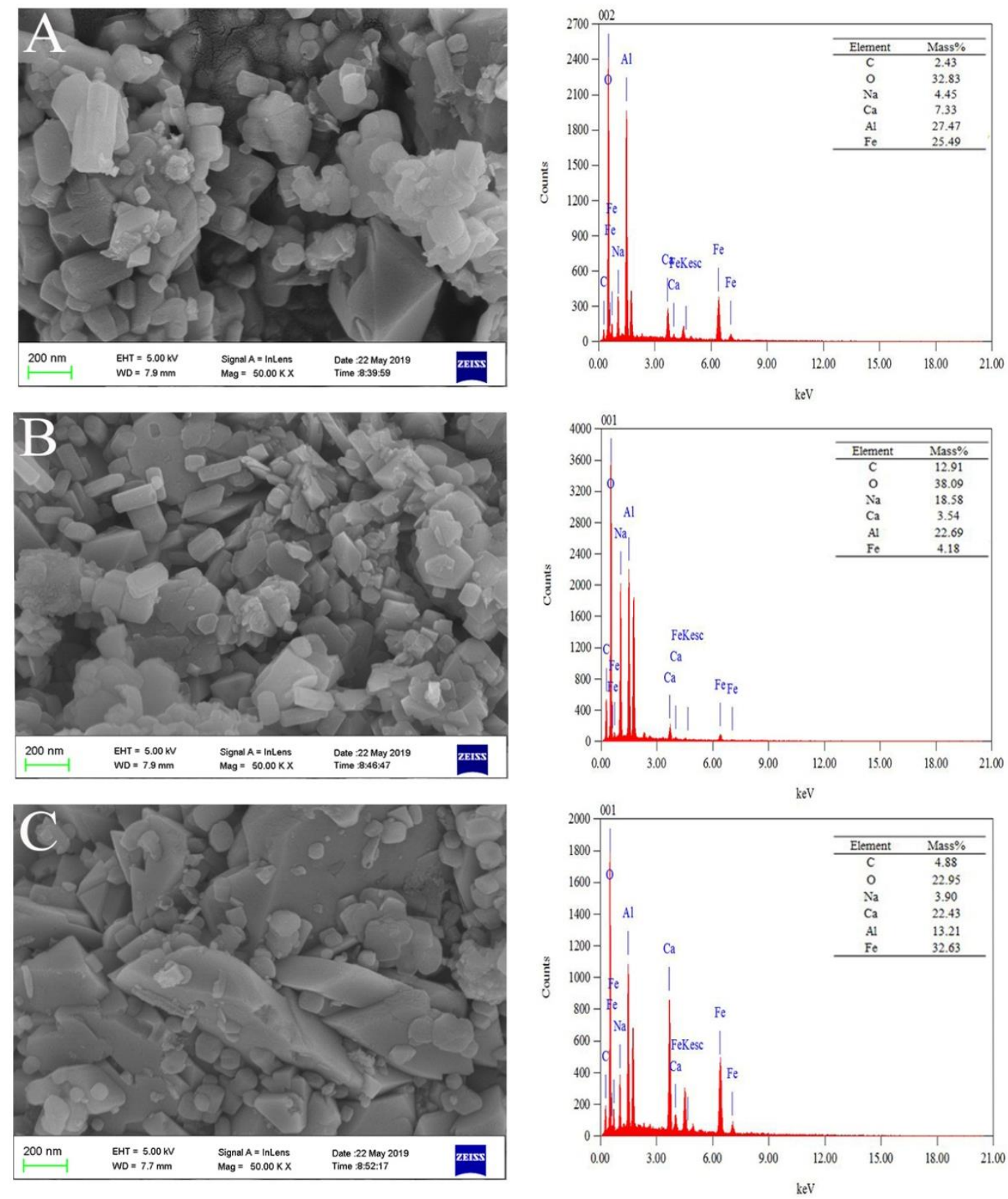

Fig.6 Morphological structure and energy-dispersive x-ray analysis spectrums of $<0.05 \mathrm{~mm}$ residue aggregates. A, Control; B,

$\mathrm{Na}^{+}(50 \mathrm{mmol} / \mathrm{L}) ; \mathrm{C}, \mathrm{Ca}^{2+}(50 \mathrm{mmol} / \mathrm{L})$

\section{Conclusion}

Aggregate behavior and stability of bauxite residue as affected by $\mathrm{Ca}^{2+} / \mathrm{Na}^{+}$additions were evaluated

313 in this study. With increasing $\mathrm{Ca}^{2+}$ content, mean weight diameter (MWD) increased due to the 

decreased with increasing electrolyte concentration. Furthermore, surface potential and electric field intensity in the $\mathrm{Ca}^{2+}$ system was lower than that in the $\mathrm{Na}^{+}$system, which may contribute to aggregate flocculation. Laser diffraction analysis allowed for continuous monitoring of aggregate disintegration during 180 minutes of circulation in solutions. Aggregate size, structure and elemental distribution changed significantly following $\mathrm{Ca}^{2+} / \mathrm{Na}^{+}$treatments. These findings provide a new approach to determine the pedogenic behavior of aggregates, whilst revealing the effects of major salt ions on aggregate stability and micromorphology. Future research should focus on application of this technique in order to reveal pedogenic aggregate behavior at bauxite residue disposal areas following ameliorant and microorganism applications.

\section{Acknowledgements}

This research received funding from the National Natural Science Foundation of China (Grant No. 41701587, 41877511), and the Fundamental Research Funds for the Central Universities of Central South University (No. 202045010).

\section{References:}

Almajmaie, A. , Hardie, M. , Acuna, T. , Birch, C., 2017. Evaluation of methods for determining soil aggregate stability. Soil Till. Res. 167, 39-45..

E. Amézketa., 1999. Soil aggregate stability: a review. J. Sustain Agr. 14(2),83-151.

Bernard Barthès, Roose, E., 2002. Aggregate stability as an indicator of soil susceptibility to runoff and erosion; validation at several levels. Catena 47(2), 0-149.

Bronick, C. J. , Lal, R., 2005. Soil structure and management: a review. Geoderma 124(1-2), 0-22.

Burke, I. T. , Peacock, C. L. , Lockwood, C. L. , Stewart, D. I. , Mortimer, R. J. G. , \& Ward, M. B. , et al., 2013. Behavior of aluminum, arsenic, and vanadium during the neutralization of red mud leachate by hcl, gypsum, or seawater. Environ. Sci. Technol. 47(12), 130605152436005.

Cui, H., Ou, Y., Wang, L., Wu, H., Yan, B., Li, Y., 2019. Distribution and release of phosphorus fractions associated with soil aggregate structure in restored wetlands. chemosphere.

Curtin, D., Steppuhn, H., Selles, F., Mermut, A.R., 1995. Sodicity in irrigated soils in Saskatchewan: Chemistry and structural stability. Can. J. Soil Sci. 75, 177-185.

Field, D. J. , Minasny, B., 1999. A description of aggregate liberation and dispersion in a horizons of australian vertisols by ultrasonic agitation. Geofis. Int. 91(1), 11-26.

Field, D.J., Minasny, B., Gaggin, M., 2006. Modelling aggregate liberation and dispersion of three soil types exposed to ultrasonic agitation. Soil. Res. 44, 497.

Graefe, M., Power, G., Klauber, C., 2012. ChemInform Abstract: Bauxite Residue Issues: Part 3. Alkalinity and Associated Chemistry. Cheminform 43, Graefe, M. , Power, G. , \& Klauber, C., 2012.

351 Guber, A., K., Pachepsky, Ya., A., Levkovsky, E., V., 2005. Fractal mass-size scaling of wetting soil 
aggregates. Ecol. Model. 182, 317-322.

Hu, F., Xu, C., Li, H., Li, S., Yu, Z., 2015. Particles interaction forces and their effects on soil aggregates breakdown. Soil Till. Res. 147, 1-9.

Jiang, C.L., Séquaris, J.M., Vereecken, H., Klumpp, E., 2012. Effects of inorganic and organic anions on the stability of illite and quartz soil colloids in $\mathrm{Na}-\mathrm{Ca}$ - and mixed $\mathrm{Na}-\mathrm{Ca}$ systems. Colloid Surface A. 415, 134-141.

Kasmerchak, C.S., Mason, J.A., Mengyu, L., 2018. Laser diffraction analysis of aggregate stability and disintegration in forest and grassland soils of northern Minnesota, usa. Geoderma, S0016706117320384-.

Kong, X., Li, M., Xue, S., Hartley, W., Chen, C., Wu, C., Li, X., Li, Y., 2017. Acid transformation of bauxite residue: Conversion of its alkaline characteristics. J. Hazard Mater. 324, 382-390.

Le Bissonnais, Y., 1996. Aggregate stability and assessment of soil crustability and erodibility: i. theory and methodology. Eur. J. Soil. Sci. 47(4), 425-437.

Le Bissonnais, Y., 2016. Aggregate stability and assessment of soil crustability and erodibility: I. Theory and methodology. Eur. J. Soil Sci. 67, 11-21.

Li, H., Hou, J., Liu, X., Li, R., Zhu, H., Wu, L., 2011. Combined Determination of Specific Surface Area and Surface Charge Properties of Charged Particles from a Single Experiment. Soil Sci. Soc. Am. J. 75(6), 2128.

Li, S., Li, H., Xu, C.Y., Huang, X.R., Xie, D.T., Ni, J.P., 2013. Particle Interaction Forces Induce Soil Particle Transport during Rainfall. Soil Sci. Soc. Am. J. 77, 1563.

Mason, J.A., Greene, R.S.B., Joeckel, R.M., 2011. Laser diffraction analysis of the disintegration of aeolian sedimentary aggregates in water. Catena 87(1), 107-118.

Mbagwu, J.S.C., Auerswald, K., 1999. Relationship of percolation stability of soil aggregates to land use, selected properties, structural indices and simulated rainfall erosion. Soil Till. Res. 50, 197-206.

Olis, A.C., 1989. Chemistry of Clays and Clay Minerals. soil sci. 147, 309.

Papadopoulos, A., Bird, N.R.A., Whitmore, A.P., Mooney, S.J., 2009. Investigating the effects of organic and conventional management on soil aggregate stability using X-ray computed tomography. Eur. J. Soil Sci. 60(3), 360-368.

Parsons, D.F., Mathias, B.M., Pierandrea, L.N., Ninham, B.W., 2011. Hofmeister effects: interplay of hydration, nonelectrostatic potentials, and ion size. Phys. Chem. Chem. Phys. 13(27), 12352.

Pashley, R.M., 1981. DLVO and hydration forces between mica surfaces in $\mathrm{Li}+, \mathrm{Na}+$, $\mathrm{K}+$, and Cs + electrolyte solutions: A correlation of double-layer and hydration forces with surface cation exchange properties. J. Colloid interf. Sci. 83, 531-546.

Pashley, R.M., Israelachvili, J.N., 1984. Molecular layering of water in thin films between mica surfaces and its relation to hydration forces. J. Colloid interf. Sci. 101, 511-523.

Santini, T.C., Kerr, J.L., Warren, L.A., 2015. Microbially-driven strategies for bioremediation of bauxite residue. J. Hazard Mater. 293, 131-157.

Santos, A.P.D., Yan, L., 2011. Ion specificity and the theory of stability of colloidal suspensions. Phys. Rev. Lett. 106(16), 167801.

Shainberg, I., Singer, M.J., 2011. Soil Response to Saline and Sodic Conditions. Agricultural Salinity Assessment and Management, 139-167.

Tang, J., Mo, Y., Zhang, J., Zhang, R., 2011. Influence of biological aggregating agents associated with 
microbial population on soil aggregate stability. Appl. Soil Ecol. 47, 153-159.

Tisdall, J.M., Oades, J.M., 1982. Organic matter and water-stable aggregates in soils. Eur. j. soil sci. 33, $141-163$

Xu, G., Ding, X., Kuruppu, M., Zhou, W., Biswas, W., 2018. Research and application of non-traditional chemical stabilizers on bauxite residue (red sand) dust control, a review. Sci. Total Environ. 616617.

Xue, S., Wang, Q., Tian, T., Ye, Y., Zhang, Y., Zhu, F., 2019. Regional-scale investigation of salt ions distribution characteristics in bauxite residue: A case study in a disposal area. J. Cent. South Univ. $26,422-429$.

Xue, S., Wu, Y., Li, Y., Kong, X., Zhu, F., William, H., Li, X., Ye, Y., 2019. Industrial wastes applications for alkalinity regulation in bauxite residue: A comprehensive review. J. Cent. South Univ. 26, 268-288.

Xue, S., Ye, Y., Zhu, F., Wang, Q., Jiang, J., Hartley, W., 2019. Changes in distribution and microstructure of bauxite residue aggregates following amendments addition. J. Environ. Sci-China. 78, 276-286.

Xue, S., Zhu, F., Kong, X., Wu, C., Huang, L., Huang, N., Hartley, W., 2016. A review of the characterization and revegetation of bauxite residues (Red mud). Environ. Sci. Pollut. R. 23, 11201132.

Yang, C., Liu, N., Zhang, Y., 2019. Soil aggregates regulate the impact of soil bacterial and fungal communities on soil respiration. Geoderma 337, 444-452.

You, F., Dalal, R., Huang, L., 2018. Initiation of soil formation in weathered sulfidic Cu-Pb-Zn tailings under subtropical and semi-arid climatic conditions. Chemosphere 204, 318-326.

You, F., Zhang, L., Ye, J., Huang, L., 2019. Microbial decomposition of biomass residues mitigated hydrogeochemical dynamics in strongly alkaline bauxite residues. Sci. Total Environ. 663, 216-226.

Zhu, F., Hou, J., Xue, S., Wu, C., Wang, Q., Hartley, W., 2017. Vermicompost and Gypsum Amendments Improve Aggregate Formation in Bauxite Residue. Land Degrad. Dev. 28, 2109-2120.

Zhu, F., Huang, N., Xue, S., Hartley, W., Li, Y., Zou, Q., 2016. Effects of binding materials on microaggregate size distribution in bauxite residues. Environ. Sci. Pollut. R. 23, 1-9.

Zeng L S, Gao Y, Li J L., 2011. Relationship between the composition of exchangeable base cation in soil aggregate and soil glomeration of greenhouse in Shouguang. J. Soil Water Conserv-China. 